\title{
Effects of Glycyrrhizin and Cortisone on Cholesterol Metabolism in the Rat
}

\author{
MASAHIRo YAMAMOTO, Nozomu TAKEUCHI, SATORU KOTANI \\ AND AKIRA KUMAGAI
}

\author{
The Third Department of Internal Medicine, School of Medicine, \\ Osaka University, Fukushima-ku, Osaka
}

\begin{abstract}
Synopsis
Effects of glycyrrhizin, an active principle of liquorice, on cholesterol metabolism, and its correlation with cortisone action were investigated using adrenalectomized rats. (1) Incorporation of acetate- $1{ }^{14} \mathrm{C}$ and mevalonate-5- ${ }^{3} \mathrm{H}$ into cholesterol of liver slices was greatly stimulated by glycyrrhizin pretreatment, i.e., 1-10 mg esp. $1 \mathrm{mg}$ per $100 \mathrm{~g}$ body weight per day intramuscularly for 5 days. Combined administration of glycyrrhizin with cortisone even weakened the stimulatory action of glycyrrhizin, although cortisone itself had a stimulatory action on cholesterogenesis. (2) Direct addition of glycyrrhizin in vitro to the incubation media containing liver slices of normal rats also increased cholesterogenesis at the concentration of $10^{-5}-10^{-3} \mathrm{M}$. (3) Excretion of intravenously injected cholesterol-4- ${ }^{14} \mathrm{C}$ into bile of bile duct-cannulated rats was much accelerated by glycyrrhizin pretreatment, $2 \mathrm{mg}$ per $100 \mathrm{~g}$ body weight per day intramuscularly for 5 days. Rates of increase of radioactivities excreted into bile by glycyrrhizin pretreatment were 4.5 times, taurocholic acid; 2.8 times, taurochenodeoxycholic acid; 2.7 times, cholesterol; and 3.7 times, total ${ }^{14} \mathrm{C}$, respectively. (4) Fecal excretion of intraperitoneally injected cholesterol-4- ${ }^{14} \mathrm{C}$ was also stimulated by glycyrrhizin pretreatment. Total ${ }^{14} \mathrm{C}$ and total bile acids $-{ }^{14} \mathrm{C}$ were increased up to about 2 times, while non-saponifiable materials- $-{ }^{14} \mathrm{C}$ and $3 \beta-\mathrm{OH}$-sterols $-{ }^{14} \mathrm{C}$ remained within 1.5 times. (5) Elimination of intravenously injected cholesterol- $-4{ }^{14} \mathrm{C}$ from plasma was accelerated by glycyrrhizin injection. (6) Glycyrrhizin treatment reduced plasma cholesterol and triglycerides levels of cholesterol diet fed rats.
\end{abstract}

Kumagai and his colleagues (Shibata, 1962) previously reported that the administration of a small amount of glycyrrhizin $(1 \mathrm{mg} / \mathrm{kg}$ body weight) to the rabbits fed a lanolin-rich diet, inhibited the elevation of plasma cholesterol level and the development of aortic atheroma. They also showed that glycyrrhizin increased both bile acid excretion and cholesterol excretion into the bile and feces.

Glycyrrhizin was considered to have corticoid-like action, presumably due to inhibitory effect on the degradation of corticosteroids in the liver (Kumagai et al., 1957), and later it was reported that glycyrrhizin had also inhibitory effects on metabolic actions of corti-

Received for publication October 5, 1970.

Presented in part at the 43rd Annual Meeting of the Japan Endocrinological Society, Osaka, March, 1970. sone (Kumagai et al., 1966a), and the corticoid itself influenced the cholesterol metabolism (Kumagai et al., 1966b).

The present experiments, therefore, were designed to investigate the effects of glycyrrhizin on the cholesterol biosynthesis and turnover in adrenalectomized rats in comparison with that of the corticosteroid, and those showed that the glycyrrhizin stimulated directly the hepatic cholesterogenesis both in vivo and in vitro, increased biliary and fecal excretion of cholesterol and bile acids and accelerated blood cholesterol turnover.

\section{Materials and Methods}

\section{Treatment of animals}

Male rats of Wistar strain, weighing about $150 \mathrm{~g}$, 
were fed a commercial laboratory chow diet (Purina) ad libitum before and during the experimental period. The animals were devided into the following 6 groups:

\begin{tabular}{|c|c|c|}
\hline & Operation & $\begin{array}{l}\text { Injection } \\
\text { (intramuscular) }\end{array}$ \\
\hline roup I & Non-adrenalectomized & Saline \\
\hline & Adrenalectomized (adx.) & Saline \\
\hline III & Adx. & $\begin{array}{l}\text { Cortisone } 1 \mathrm{mg} / 100 \\
\text { g b.w./d., } 5 \mathrm{~d} .\end{array}$ \\
\hline IV & Adx. & Cortisone $1 \mathrm{mg}$, \\
\hline & Adx. & $\begin{array}{l}\text { Cortisone } 1 \mathrm{mg}, \\
\text { Glycyrrhizin } 10 \mathrm{mg}\end{array}$ \\
\hline VI & ddx. & Glycyrrhizin $10 \mathrm{mg}$ \\
\hline
\end{tabular}

Adrenalectomy were performed under ether anesthesia. On the following day, all animals were given intramuscular injection of either saline, glycyrrhizin (Minophagen Pharmaceutical Co., Tokyo), cortisone acetate (Schering \& Co., Berlin) or both glycyrrhizin and cortisone, and the injection continued once a day for the following 5 days. The daily amounts of drugs used, were cortisone $1 \mathrm{mg}$, glycyrrhizin $1 \mathrm{mg}$ or $10 \mathrm{mg}$ per $100 \mathrm{~g}$ of body weight of animals in water suspension. On the 6th day, i.e., $12 \mathrm{hr}$ after the last injection, all animals that had been fasted for the last $12 \mathrm{hr} *$ were sacrificed by decapitation. Blood was collected by cardiac puncture and the plasma was separated for cholesterol determination according to the method of Leffler (1960). Livers of the animals were taken out immediately after sacrifice, perfused with cold saline from portal vein and sliced with a blade for incubation studies.

The effect of glycyrrhizin treatment on hypercholesteremia and hyperlipemia of the rats produced by cholesterol feeding was investigated. Twelve rats were fed a laboratory chow diet (Powdered "MF" of Oriental Yeast Co., Tokyo) containing $1 \%$ cholesterol and $0.5 \%$ cholic acid for 2 weeks, during which rats were intramuscularly injected with either $1 \mathrm{mg}$ of glycyrrhizin per $100 \mathrm{~g}$ body weight per day or saline. Triglycerides and non-esterified fatty acids (NEFA) were determined by the methods of Fletcher (1968) and Dole (1956).

The in vitro incorporation of acetate $-1-{ }^{14} \mathrm{C}$ or mevalonate- $5-{ }^{3} \mathrm{H}$ into cholesterol in the liver (Table 2, 3, 4 and 5)

Liver slices of about $250 \mathrm{mg}$ were prepared and placed in each flask containing a $2.5 \mathrm{~m} l$ of $0.1 \mathrm{M}$

* Fasting for $24 \mathrm{hr}$ suppressed hepatic cholesterogenesis but almost no suppression was found by 12 hrs' fasting. Fasting was needed to minimize the effect of dietary cholesterol on hepatic cholesterogenesis. (Table 2)
Krebs-Ringer-phosphate buffer ( $\mathrm{pH} 7.4$ ) added either $5 \mu \mathrm{Ci}$ of sodium acetate- $1-{ }^{14} \mathrm{C}$ (specific activity 9.7 $\mathrm{mC} / \mathrm{m}$ mole, Daiichi Pure Chemicals Co., Tokyo) or $2.5 \mu \mathrm{Ci}$ of $\mathrm{DL}-$ mevalonic acid $-5-{ }^{3} \mathrm{H}$ (specific activity $3.75 \mathrm{mC} / \mathrm{m}$ mole, New England Nuclear Corp., Boston, Mass). and $20 \mu$ moles of glucose. Incubation was carried out for $2 \mathrm{hr}$ in a $95 \% \mathrm{O}_{2}-5 \% \mathrm{CO}_{2}$ atmosphere at $37^{\circ} \mathrm{C}$ in a Dubnoff metabolic shaking incubator. At the end of the incubation period, $2 \mathrm{~m} l$ of $5 \%$ alcoholic $\mathrm{KOH}$ solution was added to each flask, the content of which was hydrolyzed for $2 \mathrm{hr}$ at $65^{\circ} \mathrm{C}$. From the hydrolysates, non-saponifiable materials were extracted 4 times with petroleum ether and the extract was washed 5 times with water (Kumagai et al., 1966b) and cholesterol fraction was separated by digitonization. The cholesterol fraction precipitated by digitonization was washed once with acetoneether $(1: 2)$ mixture, twice with ether and dissolved in $2 \mathrm{ml}$ of methanol. An aliqout of the methanol solution was used for cholesterol determination. Another aliquot was assayed for the radioactivity using a scintillator consisted of $5 \mathrm{~g}$ PPO and $300 \mathrm{mg}$ POPOP in 11 of toluene by a Packard liquid scintillation spectrometer model 3003 with correction of the quenching by the channel ratio method.

Student $\mathrm{T}$ test for statistical analysis was applied for all values obtained in this report.

Free sterols were regenerated from the digitonides according to Sperry (1963). The precipitate of sterol digitonides was dissolved in pyridine and free sterols were extracted with diethyl ether. After being dried in vacuo, the free sterols were redissolved in chloroform. Gas liquid chromatography of standard cholesterol, cholestanol, and lanosterol as well as that of tissue sterols was carried out in a F \& $\mathrm{M}$ high efficiency gas chromatograph model 402 (Hewlett-Packard, F \& M Scientific Div., Avondale, Pa.). The $6 \mathrm{ft}$ column was packed with Gas-chrom $\mathrm{S}$ coated with $1 \% \mathrm{QF}-1$. The gas phase, argon. The column temperature, $200^{\circ} \mathrm{C}$. A half of the effluent was trapped with Pasteur pipettes. The inside of the pipettes was washed with ether and the radioactivities of corresponding peaks were determined (Table 5).

The in vivo incorporation of acetate $-1-{ }^{14} \mathrm{C}$ into cholesterol in liver of bile duct-ligated rats (Table 6)

Twelve rats, weighing about $150 \mathrm{~g}$, had their bile ducts ligated immediately after adrenalectomy. Either $1 \mathrm{mg}$ or $10 \mathrm{mg}$ of glycyrrhizin per $100 \mathrm{~g}$ of body weight was injected intramuscularly into 8 of them daily for 5 days and the other 4 rats served as control.

On the 6th day of treatment, $12 \mathrm{hr}$ after the last injection of glycyrrhizin, all animals were given intravenously $10 \mu \mathrm{Ci}$ of sodium acetate $-1-{ }^{14} \mathrm{C}$ per $100 \mathrm{~g}$ body weight, and sacrificed by decapitation $30 \mathrm{~min}$ 
after the isotope injection. Cholesterol concentration in the plasma and liver, as well as the incorporation of labeled acetate into both hepatic total lipids and cholesterol were determined. One $\mathrm{g}$ of liver or one $\mathrm{m} l$ of plasma from the animals was treated with $25 \mathrm{ml}$ of chloroform-methanol (2:1) mixture using a glass homogenizer and the extract was washed twice with water and twice with water-methanol-chloroform (46:47:3) mixture and evaporated to dryness under $\mathrm{N}_{2}$ at $40^{\circ} \mathrm{C}$. An aliquot of the chloroform-methanol solution of the extract was used for the determination of radioactivity of total lipids. Saponification and cholesterol extraction were carried out, as mentioned previously.

\section{In vitro effect of glycyrrhizin on cholesterogenesis in normal rat liver slices (Table 7)}

Livers of healthy normal rats were cut into slices. Each slice weighing about $500 \mathrm{mg}$ was incubated in $2.5 \mathrm{ml}$ of $0.67 \mathrm{M}$ phosphate buffer containing $5 \mu \mathrm{Ci}$ of sodium acetate $-1-{ }^{14} \mathrm{C}$, various amounts of glycyrrhizin $(0.01,0.03,0.1,0.8$ and $8 \mathrm{mg}$ per $\mathrm{m} l$ of incubation mixture respectively and $20 \mu$ moles of glucose. The incorporation of the labeled acetate into total lipids and cholesterol was determined using the same incubation method described above. Watery solution of glycyrrhizin was the gift from Minophagen Pharmaceutical Co., Ltd., Tokyo.

\section{The excretion of injected cholesterol-4-14 $\mathrm{C}$ and its metabolites into bile (Table 8 )}

Ten rats weighing about $150 \mathrm{~g}$ were devided into 2 groups. Five male rats were given intramuscular injections of $2 \mathrm{mg}$ of glycyrrhizin per $100 \mathrm{~g}$ body weight per day for 5 days. The other 5 rats were given saline injection correspondingly. Three hr after the last injection, bile ducts of all animals were cannulated under hexobarbital anesthesia. One hour after the operation, $0.25 \mu \mathrm{Ci}$ of cholesterol-4 ${ }^{14} \mathrm{C}^{*}$ (specific activity $30 \mathrm{mC} / \mathrm{m}$ mole, The Radiochemical Centre, England) per $100 \mathrm{~g}$ body weight was intravenously injected and then bile was collected for $24 \mathrm{hr}$.

An aliquot of bile was used for the determination of radioactivity of total ${ }^{14} \mathrm{C}$ excreted. An equal volume of ethanol was added to bile and centrifuzed. After the supernatant fraction was evaporated, the residue was dissolved in ethanol-chloroform $(5: 2)$. Taurocholic acid, tauro-dihydroxy-cholanic acids, glycocholic acid and sterols were separated by the thin-layer

\footnotetext{
* The radiochemical purity of cholesterol-4-4 ${ }^{14} \mathrm{C}$ was checked by paper chromatography before use. The purity was found to be $99.3 \%$. Cholesterol was suspended in saline with Tween 80 .
}

chromatography on Silica gel H, $250 \mu$ thick. Developing solvent system was isoamyl alcohollacetic acidwater (18: 5:2) according to Hara et al. (1964). Spots were detected with iodine vapor, the adsorbent was scraped off. Bile acids were eluted with $2 \%$ acetic acid in methanol and cholesterol was eluted with chloroform-methanol $(1: 1)$. Radioactivities of these fractions were determined by a Nuclear Chicago liquid scintillation counter Mark I. Counting efficiency and quenching were corrected by the external standard method. The excretory rate of each fraction into bile was calculated as follows: $\mathrm{dpm}$ in bile/dpm of cholesterol $-4-{ }^{14} \mathrm{C}$ injected.

\section{The excretion of injected cholesterol-4-14 $C$ and its metabolites into feces (Table 9)}

Ten rats weighing about $150 \mathrm{~g}$ were devided into 2 groups. Daily injections of glycyrrhizin and saline were carried out for 5 days as described in the experimental procedures about the excretion of cholesterol into bile. On the fourth day and $4 \mathrm{hr}$ after the fourth treatment of glycyrrhizin, $0.25 \mu \mathrm{Ci}$ of cholesterol $-4-{ }^{14} \mathrm{C}$ per $100 \mathrm{~g}$ body weight was intraperitoneally injected and then feces were collected for $48 \mathrm{hr}$. Feces was homogenized in an equal weight of water and refluxed in 10 volumes of hot ethanol for $24 \mathrm{hr}$. An aliquot of the ethanol extract of feces was used for determination of the total ${ }^{14} \mathrm{C}$ excreted. Another aliquot of the ethanol extract of the feces was made alkaline by addition of one fifth volume of $10 \mathrm{~N} \mathrm{KOH}$ and saponified at 2 atmosphere for $2 \mathrm{hr}$. The non-saponifiable materials were extracted 3 times with 5 volumes of petroleum ether. The extract was mixed and washed 4 times water. $3 \beta$-Hydroxysterols were precipitated by usual digitonin method and the precipitates were washed with acetone-ether (1:2) and with ether. After the extraction of the non-saponifiable materials, the water phase was acidified to $\mathrm{pH} 1$ with concentrated $\mathrm{HCl}$ and total bile acids were extracted 3 times by 5 volumes of diethyl ether. The extract was mixed and washed 4 times with water.

\section{The effect of glycyrrhizin and cortisone on the disappearance of cholesterol-4-14 $\mathrm{C}$ from the peripheral blood (Table 10 )}

Adrenalectomized rats weighing about $150 \mathrm{~g}$ were given intramuscular injections of either glycyrrhizin $10 \mathrm{mg}$, cortisone $1 \mathrm{mg}$ per $100 \mathrm{~g}$ body weight or saline daily for 8 days. On the 6th day, all animals were intraperitoneally administered $1 \mu \mathrm{Ci}$ of cholesterol$4-{ }^{14} \mathrm{C}$ per $100 \mathrm{~g}$ body weight and were sacrificed on the 8 th day or $48 \mathrm{hr}$ after the isotope injection. Total lipid fraction from one $\mathrm{m} l$ of the plasma of the animals was used for determination of cholesterol radioactivity which remained in the plasma. 
Table 1. Effects of glycyrrhizin and/or cortisone administration on the plasma lipid levels of normal diet fed adrenalectomized rats and of cholesterol diet fed nonadrenalectomized rats

Normal diet fed

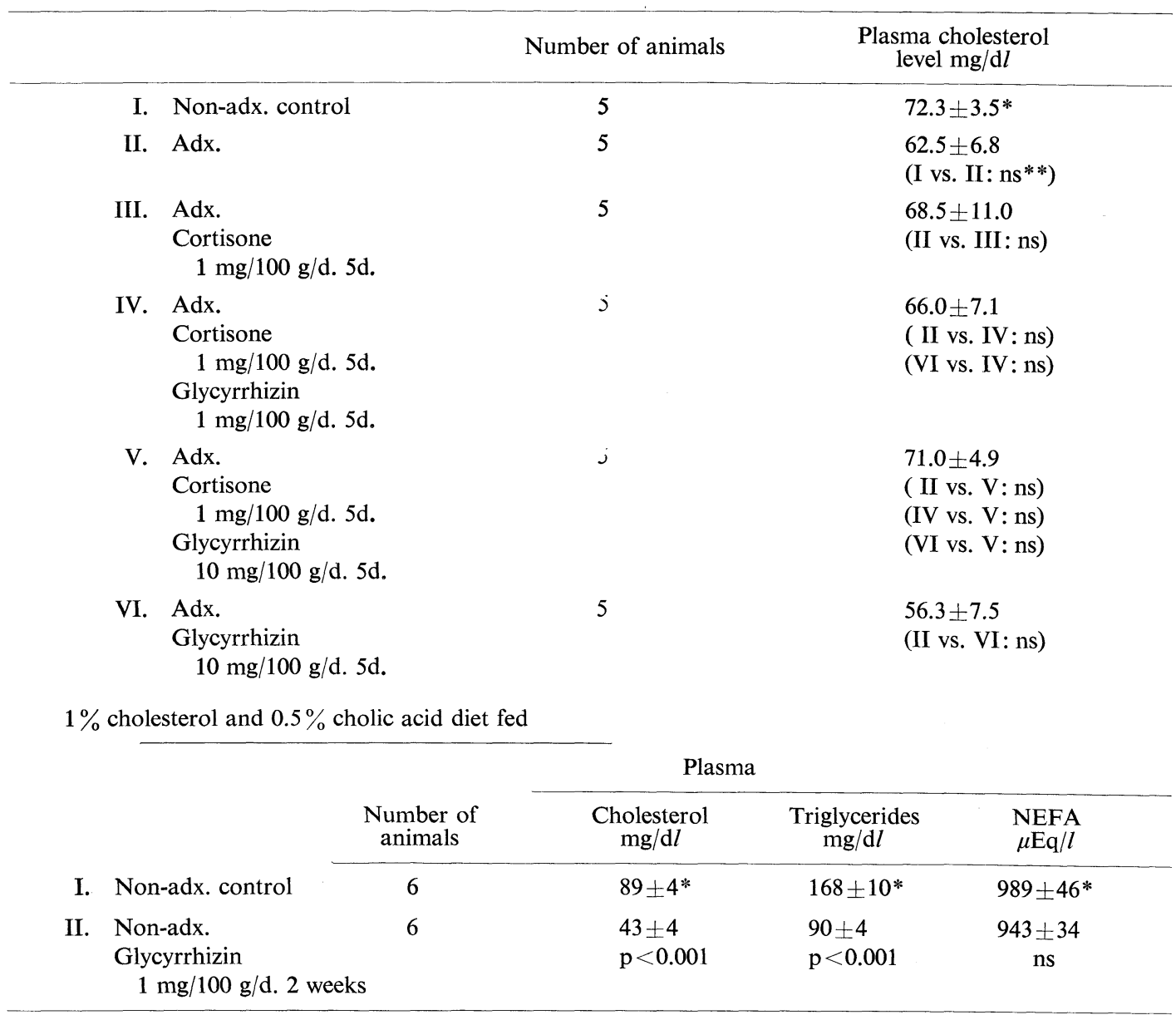

* Mean \pm standard error

** ns: Non-significant

Adx.: Adrenalectomized

\section{Results}

Effects of the cortisone and/or glycyrrhizin administration on the plasma cholesterol level of normal and cholesterol diet fed rats (Table 1 )

There were no significant differences in the plasma cholesterol levels among experimental groups fed a normal diet. Hypercholesteremia and hypertriglyceridemia produced by cholesterol feeding were much improved by glycyrrhizin treatment. On the contrary, no change was observed in NEFA.
Effects of the cortisone and/or glycyrrhizin administration on the in vitro incorporation of acetate $-1{ }^{14} \mathrm{C}$ or mevalonic acid $-5-{ }^{3} \mathrm{H}$ into cholesterol by the liver-slices of the adrenalectomized rats (Table 2, 3, 4 and 5)

Rats of the cortisone-treated group (group III) showed a significant increase in the incorporation of acetate-1-1 ${ }^{14} \mathrm{C}$ into both non-saponifiable materials and total cholesterol, compared with the adrenalectomized rats (group II) (Table 3). Glycyrrhizin markedly increased the incorporation of the labeled precursor into both fractions, the higher extent being in the total cholesterol fraction. In the rats of the glycyrrhizin- 
Table 2. The effect of fasting on hepatic cholesterogenesis from $5 \mu \mathrm{Ci}$ of acetate $-1-{ }^{14} \mathrm{C}$ by liver slices of non-adrenalectomized rats $(250 \mathrm{mg}, 2 \mathrm{hr})$

\begin{tabular}{lcc}
\hline \hline & $\begin{array}{c}\text { No. of } \\
\text { animals }\end{array}$ & $\begin{array}{c}\text { Radioactivity of total } \\
\text { cholesterol } \\
\text { dpm }\end{array}$ \\
\hline Control & 4 & $2,150 \pm 420 *$ \\
Fasted for $6 \mathrm{hr}$ & 4 & $2,310 \pm 310 * *$ \\
Fasted for $12 \mathrm{hr}$ & 4 & $1,960 \pm 250 * *$ \\
Fasted for $24 \mathrm{hr}$ & 4 & $930 \pm 170 * *$ \\
\hline$*$ Mean \pm standard error & $* *$ Non-significant \\
$* * * \mathrm{p}<0.05$ &
\end{tabular}

treated group (group VI), the radioactivities in both fractions were respectively 48 times and 99 times greater than those of the adrenalectomized rats (group II), and the specific activity of the total cholesterol of the former group was 67.4 times higher than that of the latter one. Through the combined treatment of cortisone and glycyrrhizin (group IV \& V), the incorporation of labeled acetate into both fractions was between those in group III \& VI.

The radioactivity of $3 \beta$-hydroxysterols precipitated from the non-saponifiable materials as the digitonides was mainly derived of cholesterol in both adrenalectomized controls and adrenalectomized, glycyrrhizin-treated rats as shown in Table 5.

Table 4 shows the result of the incorporation into the two fractions using mevalonic acid $-5-{ }^{3} \mathrm{H}$. Adrenalectomy (group II) resulted in a decrease of the incorporation, while cortisone administration to adrenalectomized rats (group III) restored or even increased the incorporation of the labeled mevalonic acid into total cholesterol. Glycyrrhizin treatment (group VI) caused a greater increase in the incorporation than cortisone treatment and 5.7 and 47.5 fold greater incorporation respectively into both nonsaponifiable and total cholesterol fractions was obtained by glycyrrhizin treatment compared with controls. The specific activity of total cholesterol of group VI was 33.0 times greater than that of group II. Thus both glycyrrhizin and cortisone influenced much more the incorporation of mevalonate into the total cholesterol fraction than into the non-saponifiable materials (Table 4). It might be suspected that glycyrrhizin and cortisone accelerated cholesterol biosynthesis via various intermediates.

The effect of the glycyrrhizin on the in vivo incorporation of acetate $-1-{ }^{14} \mathrm{C}$ into cholesterol in

Table 3. Effects of glycyrrhizin and/or cortisone administration on the incorporation of acetate-1-14 $\mathrm{C}$ into non-saponifiable materials and total cholesterol by slices of livers $(250 \mathrm{mg})$ of adrenalectomized rats

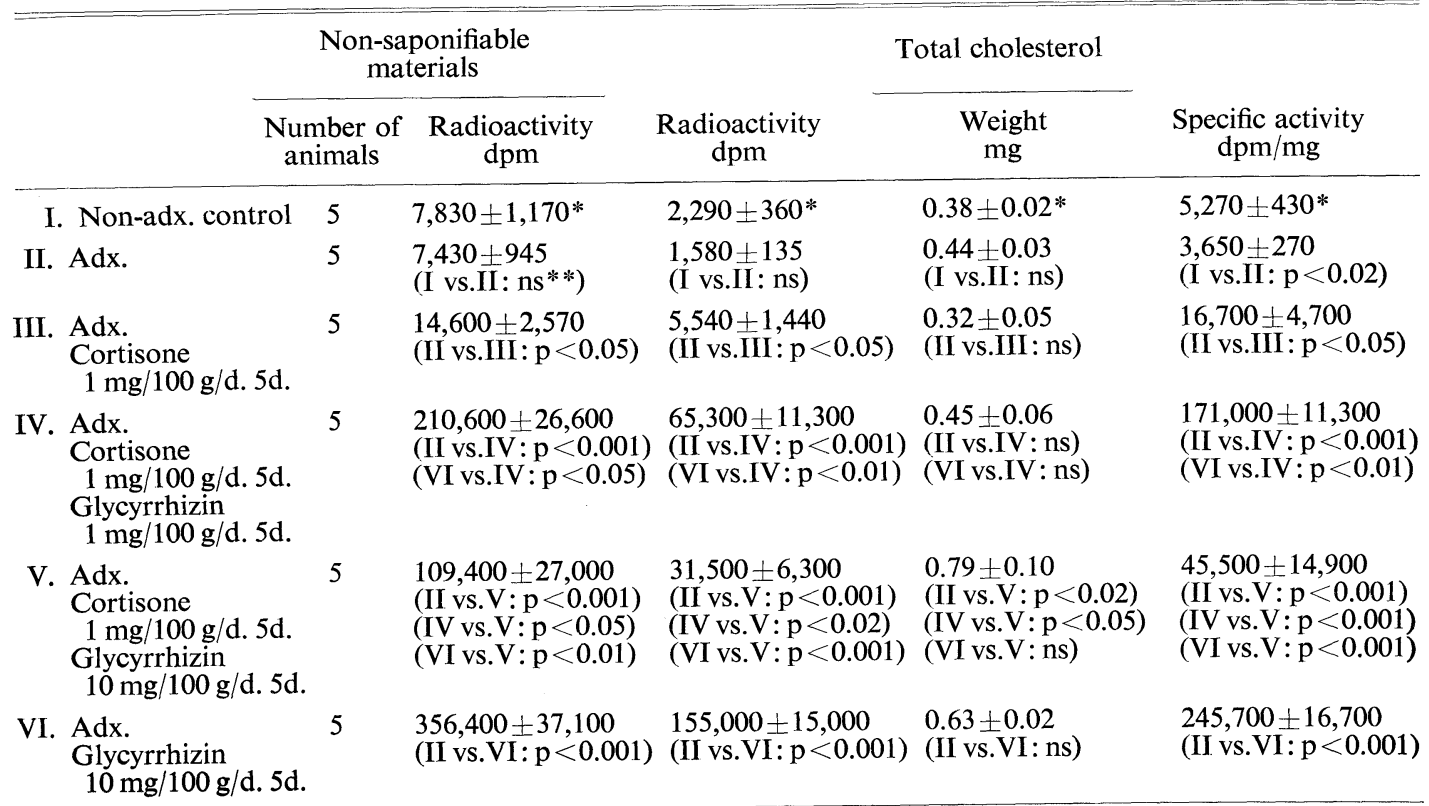


Table 4. Effects of glycyrrhizin and/or cortisone administration on the incorporation of mevalonic acid- $5-{ }^{3} \mathrm{H}$ into non-saponifiable materials and total cholesterol by slices of livers $(250 \mathrm{mg})$ of adrenalectomized rats

\begin{tabular}{|c|c|c|c|c|c|c|}
\hline & & \multicolumn{2}{|c|}{$\begin{array}{l}\text { Non-saponifiable } \\
\text { materials }\end{array}$} & \multirow[b]{2}{*}{$\begin{array}{l}\text { Radioactivity } \\
\text { dpm }\end{array}$} & \multirow{2}{*}{$\begin{array}{c}\text { Total cholesterol } \\
\begin{array}{c}\text { Weight } \\
\mathrm{mg}\end{array}\end{array}$} & \multirow[b]{2}{*}{$\begin{array}{l}\text { Specific activity } \\
\mathrm{dpm} / \mathrm{mg}\end{array}$} \\
\hline & & $\begin{array}{l}\text { umber of } \\
\text { animals }\end{array}$ & $\begin{array}{l}\text { Radioactivity } \\
\text { dpm }\end{array}$ & & & \\
\hline & Non-adx. control & 5 & $19,900 \pm 720^{*}$ & $2,660 \pm 225$ & $0.38 \pm 0.02$ & $6,530 \pm 770$ \\
\hline & Adx. & 5 & $\begin{array}{l}14,400 \pm 1,395 \\
\text { (I vs.II: } \mathrm{p}<0.02 \text { ) }\end{array}$ & $\begin{array}{l}1,260 \pm 90 \\
\text { (I vs.II: } p<0.01)\end{array}$ & $\begin{array}{l}0.44 \pm 0.03 \\
\text { (I vs.II: ns**) }\end{array}$ & $\begin{array}{l}2,880 \pm 320 \\
(\text { I vs.II: } \mathrm{p}<0.01)\end{array}$ \\
\hline & $\begin{array}{l}\text { Adx. } \\
\text { Cortisone } \\
1 \mathrm{mg} / 100 \mathrm{~g} / \mathrm{d} .5 \mathrm{~d} .\end{array}$ & 5 & $\begin{array}{l}16,800 \pm 2,520 \\
\text { (II vs.III : ns) }\end{array}$ & $\begin{array}{l}6,210 \pm 1,260 \\
\text { (II vs.III: } \mathrm{p}<0.01 \text { ) }\end{array}$ & $\begin{array}{l}0.32 \pm 0.05 \\
\text { (II vs.III: ns) }\end{array}$ & $\begin{array}{l}18,700 \pm 3,000 \\
\text { (II vs.III: } p<0.001 \text { ) }\end{array}$ \\
\hline & $\begin{array}{l}\text { Adx. } \\
\text { Cortisone } \\
1 \mathrm{mg} / 100 \mathrm{~g} / \mathrm{d} .5 \mathrm{~d} . \\
\text { Glycyrrhizin } \\
1 \mathrm{mg} / 100 \mathrm{~g} / \mathrm{d} .5 \mathrm{~d} .\end{array}$ & 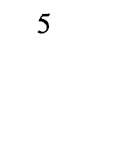 & $\begin{array}{l}58,100 \pm 5,400 \\
(I I \text { vs.IV }: p<0.001) \\
\text { (VI vs.IV: ns) }\end{array}$ & $\begin{array}{l}38,900 \pm 3,200 \\
(\text { II vs.IV }: p<0.001) \\
(\text { VI vs.IV }: p<0.02)\end{array}$ & $\begin{array}{l}0.45 \pm 0.06 \\
\text { (II vs.IV: ns) } \\
\text { (VI vs.IV: ns) }\end{array}$ & $\begin{array}{l}89,500 \pm 5,900 \\
\text { (II vs.IV : } \mathrm{p}<0.001) \\
\text { (VI vs.IV: ns) }\end{array}$ \\
\hline & $\begin{array}{l}\text { Adx. } \\
\text { Cortisone } \\
1 \mathrm{mg} / 100 \mathrm{~g} / \mathrm{d} .5 \mathrm{~d} \text {. } \\
\text { Glycyrrhizin } \\
10 \mathrm{mg} / 100 \mathrm{~g} / \mathrm{d} .5 \mathrm{~d} .\end{array}$ & 5 & $\begin{array}{l}48,200 \pm 5,400 \\
\text { (II vs.V: } \mathrm{p}<0.001) \\
\text { (IV vs.V:ns) } \\
\text { (VI vs.V: } \mathrm{p}<0.05 \text { ) }\end{array}$ & $\begin{array}{l}36,000 \pm 4,100 \\
(\text { II vs.V: } \mathrm{p}<0.001) \\
\text { (IV vs.V: ns) } \\
\text { (VI vs.V: } \mathrm{p}<0.05 \text { ) }\end{array}$ & $\begin{array}{l}0.79 \pm 0.10 \\
(I I \text { vs.V: } \mathrm{p}<0.02) \\
\text { (IV vs.V: } \mathrm{p}<0.05 \text { ) } \\
\text { (VI vs.V: ns) }\end{array}$ & $\begin{array}{l}47,300 \pm 5,400 \\
\text { (II vs.V: } \mathrm{p}<0.001) \\
\text { (IV vs. V: } \mathrm{p}<0.01 \text { ) } \\
\text { (VI vs.V: } \mathrm{p}<0.01 \text { ) }\end{array}$ \\
\hline & $\begin{array}{l}\text { Adx. } \\
\text { Glycyrrhizin } \\
10 \mathrm{mg} / 100 \mathrm{~g} / \mathrm{d} .5 \mathrm{~d} .\end{array}$ & 5 & $\begin{array}{l}81,900 \pm 12,150 \\
\text { (II vs.VI: } \mathrm{p}<0.001 \text { ) }\end{array}$ & $\begin{array}{l}59,900 \pm 4,800 \\
\text { (II vs.VI }: p<0.001)\end{array}$ & $\begin{array}{l}0.63 \pm 0.02 \\
\text { (II vs.VI: } \mathrm{p}<0.001 \text { ) }\end{array}$ & $\begin{array}{l}95,400 \pm 7,700 \\
\text { (II vs.VI: } p<0.001)\end{array}$ \\
\hline
\end{tabular}

Table 5. Sterol synthesis in vitro from acetate $-1-{ }^{14} \mathrm{C}(5 \mu \mathrm{Ci})$ by liver slices of control and glycyrrhizin-treated rats $(250 \mathrm{mg})$ : Result of gas-liquid chromatographic analysis

\begin{tabular}{|c|c|c|c|}
\hline & \multicolumn{3}{|c|}{ Radioactivity (dpm) } \\
\hline & $\begin{array}{l}\text { Total digitonin- } \\
\text { precipitable sterols }\end{array}$ & Cholesterol & Lanosterol \\
\hline Adrenalectomized & $\begin{array}{l}1,660 \\
(100 \%)\end{array}$ & $\begin{array}{l}1,490 \\
(90 \%)\end{array}$ & $\begin{array}{l}321 \\
(2 \%)\end{array}$ \\
\hline $\begin{array}{l}\text { Adrenalectomized, glycyrrhizin-treated } \\
10 \mathrm{mg} / 100 \mathrm{~g} / \text { day } 5 \text { days }\end{array}$ & $\begin{array}{l}128,000 \\
(100 \%)\end{array}$ & $\begin{array}{l}119,000 \\
\quad(93 \%)\end{array}$ & $\begin{array}{l}1,290 \\
(1 \%)\end{array}$ \\
\hline
\end{tabular}

Values are averages of 3 samples.

the liver of adrenalectomized rats with bile duct ligation

As shown in the Table 6, the in vivo hepatic lipogenesis and cholesterogenesis also increased through a small dose of glycyrrhizin, though the effect on the cholesterogenesis was not so remarkable as that observed in the adrenalectomized rats without bile duct ligation.

The effect of the direct addition of glycyrrhizin to the incubation medium on the hepatic cholesterogenesis (Table 7)
A smaller amount of glycyrrhizin $(0.03-0.8 \mathrm{mg} / \mathrm{m} l$ of incubation medium) increased hepatic cholesterogenesis and lipogenesis in vitro and maximum values were attained at $0.1 \mathrm{mg} / \mathrm{m} l$. The increase of hepatic cholesterogenesis by the addition of glycyrrhizin in vitro was not so marked as that observed in the in vivo experiment using rats pretreated with glycyrrhizin.

The effect of glycyrrhizin administration on excretion of intravenously injected cholesterol-4${ }^{14} \mathrm{C}$ and its metabolites into bile

The radioactivities of bile acids- ${ }^{14} \mathrm{C}$ and choles- 
Table 6. The effect of glycyrrhizin administration on the in vivo incorporation of acetate $-1-{ }^{14} \mathrm{C}$ into total lipids and cholesterol in the liver of adrenalectomized, bile duct-ligated rats

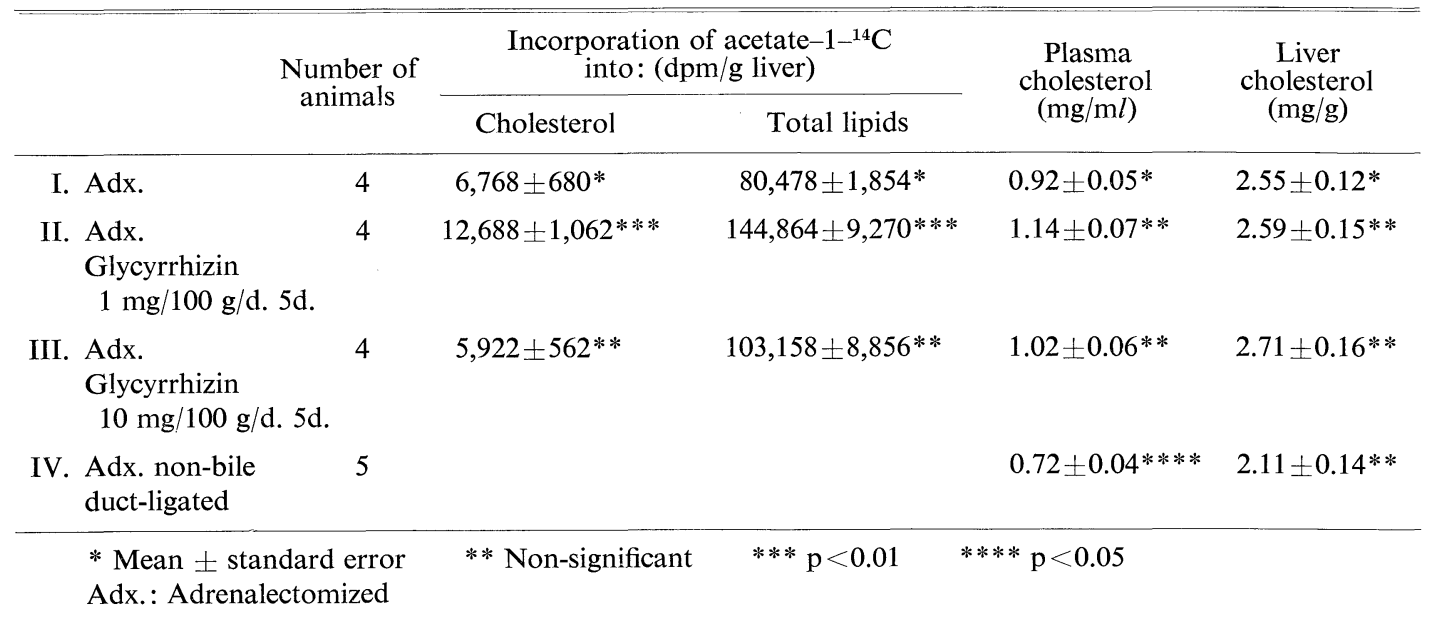

Table 7. The effect of the direct addition of glycyrrhizin to the incubation medium on cholesterogenesis in vitro in liver slices of the rat

\begin{tabular}{|c|c|c|c|c|}
\hline \multirow{2}{*}{$\begin{array}{c}\text { Concentration } \\
\text { of } \\
\text { glycyrrhizin }\end{array}$} & & \multirow{2}{*}{$\begin{array}{c}\text { Number } \\
\text { of } \\
\text { flasks }\end{array}$} & \multicolumn{2}{|c|}{ Incorporation of acetate $-1-{ }^{14} \mathrm{C}$ into: } \\
\hline & & & Cholesterol & Total lipids \\
\hline $\mathrm{mg} / \mathrm{m} l$ & Mol. & & $\mathrm{dpm} / \mathrm{g}$ liver & $\mathrm{dpm} / \mathrm{g}$ liver \\
\hline Control & & 6 & $5,640 \pm 410^{*}$ & $67,100 \pm 2,200 *$ \\
\hline 0.01 & $1.2 \times 10^{-5}$ & 6 & $6,060 \pm 430 * *$ & $68,000 \pm 3,600 * *$ \\
\hline 0.03 & $3.5 \times 10^{-5}$ & 6 & $9,200 \pm 490 * * * *$ & $101,000 \pm 3,500 * * * * *$ \\
\hline 0.1 & $1.2 \times 10^{-4}$ & 6 & $12,600 \pm 800 * * * *$ & $147,000 \pm 5,200 * * * * *$ \\
\hline 0.8 & $1.0 \times 10^{-3}$ & 4 & $10,600 \pm 1,300 * * *$ & $121,000 \pm 12,800 * * * *$ \\
\hline 8.0 & $1.0 \times 10^{-2}$ & 4 & $5,380 \pm 410 * *$ & $89,700 \pm 7,400 * * *$ \\
\hline
\end{tabular}

terol- ${ }^{14} \mathrm{C}$ excreted into bile after cholesterol-4-4 ${ }^{14} \mathrm{C}$ injection were shown in Table 8 . The volume of bile collected for $24 \mathrm{hr}$ after isotope injection was not changed by glycyrrhizin treatment. Radioactivities of total ${ }^{14} \mathrm{C}$, taurocholic acid, taurochenodeoxycholic acid and sterols excreted into bile, however, were much increased by glycyrrhizin pretreatment. The rate of increase by glycyrrhizin in radioactivity of total ${ }^{14} \mathrm{C}$ excreted was 3.7 ; of taurocholic acid, 4.5; taurochenodeoxycholic acid, 2.8; sterols*, 2.7, respectively. The ratio of taurocholic acid vs. taurochenodeoxycholic acid vs. cholesterol expressed as radioactivities excreted into bile of normal rats was $10: 1: 3$, while it increased up to $16: 1: 3$ in that of glycyrrhizin-treated

* Gas chromatographic analysis showed that this fraction mainly consisted of cholesterol. rats.

The biliary excrtion of radioactive cholesterol and its metabolites was greater in the first $12 \mathrm{hr}$ of bile collection than in the second $12 \mathrm{hr}$ in both normal and glycyrrhizin-treated groups.

The effect of glycyrrhizin administration on excretion of intraperitoneally injected cholesterol$4^{4-14} \mathrm{C}$ and its metabolites into feces

The radioactivities of bile acids $-{ }^{14} \mathrm{C}$ and sterols${ }^{14} \mathrm{C}$ excreted into feces after cholesterol $-4-{ }^{14} \mathrm{C}$ injection were shown in Table 9. The weight of feces collected for $48 \mathrm{hr}$ after radioactive cholesterol-4- ${ }^{14} \mathrm{C}$ injection was not changed by glycyrrhizin treatment. Radioactivities of total ${ }^{14} \mathrm{C}$, total bile acids $-{ }^{14} \mathrm{C}$, non-saponifiable materials $-{ }^{14} \mathrm{C}$ and $3 \beta-\mathrm{OH}$-sterols $-{ }^{14} \mathrm{C}$ excreted into feces, however, were much increased by glycy- 
Table 8. The effect of glycyrrhizin administration on excretion of intravenously injected cholesterol-4-4 ${ }^{14} \mathrm{C}$ and its metabolites into bile collected for $24 \mathrm{hr}$ in bile duct-cannulated rats

\begin{tabular}{|c|c|c|c|c|c|c|}
\hline & \multirow[b]{2}{*}{$\begin{array}{l}\text { No. of } \\
\text { rats }\end{array}$} & \multirow[b]{2}{*}{$\begin{array}{l}\text { Volume of } \\
\text { bile }(\mathrm{m} l)\end{array}$} & \multicolumn{4}{|c|}{ Excretory rate of injected cholesterol $-4-{ }^{14} \mathrm{C}$ into bile as: } \\
\hline & & & $\begin{array}{l}\text { Total } \\
{ }^{14} \mathrm{C} \\
(\%) \dagger\end{array}$ & $\begin{array}{c}\text { Taurocholic } \\
\underset{(\%) \dagger}{\text { acid-14 }} \mathrm{C}\end{array}$ & $\begin{array}{l}\text { aurochenodeoxy- } \\
\text { cholic acid-14 } \mathrm{C} \\
\qquad(\%) \dagger\end{array}$ & $\underset{(\%)}{\text { Sterols- }{ }^{14} \mathrm{C}}$ \\
\hline $\begin{array}{l}\text { Saline-treated } \\
\text { control }\end{array}$ & 5 & $9.3 \pm 1.0 *$ & $12.37 \pm 1.19 *$ & $6.63 \pm 0.64 *$ & $0.66 \pm 0.04 *$ & $2.24 \pm 0.43 *$ \\
\hline $\begin{array}{l}\text { Glycyrrhizin- } \\
\text { treated } \\
2 \mathrm{mg} / 100 \mathrm{~g} / \mathrm{d} .5 \mathrm{~d} \text {. }\end{array}$ & 5 & $11.8 \pm 1.6 * *$ & $43.95 \pm 4.25 * * * *$ & $* 29.51 \pm 3.88 * * * *$ & $* 1.85 \pm 0.16 * * * * *$ & $5.99 \pm 0.49 * * * *$ \\
\hline $\begin{array}{l}\text { Rate of increase } \\
\text { by glycyrrhizin } \\
\text { treatment } \\
\text { (control: } 1 \text { ) }\end{array}$ & & & 3.7 & 4.5 & 2.8 & 2.7 \\
\hline $\begin{array}{l}\text { Adrenalectomized, } \\
\text { saline-treated } \\
\text { control }\end{array}$ & 5 & $8.1 \pm 1.1 * *$ & $10.86 \pm 1.35 * *$ & $5.89 \pm 0.80 * *$ & $0.59 \pm 0.05 * *$ & $1.82 \pm 0.39 * *$ \\
\hline
\end{tabular}

* Mean \pm standard error $\quad * *$ Non-significant $\quad * * * \mathrm{p}<0.05 \quad * * * * \mathrm{p}<0.005$

$* * * * * \mathrm{p}<0.001 \quad \dagger$ Percentage of dpm excreted/dpm injected

Table 9. The effect of glycyrrhizin administration on excretion of intraperitoneally injected cholesterol $-4-{ }^{14} \mathrm{C}$ and its metabolites into feces of rats collected for $48 \mathrm{hr}$

\begin{tabular}{|c|c|c|c|c|c|}
\hline & \multirow[b]{2}{*}{$\begin{array}{l}\text { No. of } \\
\text { rats }\end{array}$} & \multicolumn{4}{|c|}{ Excretory rate of injected cholesterol- $4-{ }^{14} \mathrm{C}$ into feces as: } \\
\hline & & $\begin{array}{l}\text { Total }{ }^{14} \mathrm{C} \\
(\%) \dagger\end{array}$ & $\begin{array}{c}\text { Total bile } \\
\text { acids-14 } \mathrm{C} \\
(\%) \dagger\end{array}$ & $\begin{array}{c}\text { Non-saponifiable } \\
\text { materials-14 } \mathrm{C} \\
(\%)^{\dagger}\end{array}$ & $\underset{(\%) \dagger}{3 \beta-\mathrm{OH}-\text { sterols- }{ }^{14} \mathrm{C}}$ \\
\hline $\begin{array}{l}\text { Saline-treated } \\
\text { control }\end{array}$ & 5 & $20.04 \pm 2.72 *$ & $8.40 \pm 1.05 *$ & $6.25 \pm 0.65 *$ & $5.10 \pm 0.19^{*}$ \\
\hline $\begin{array}{l}\text { Glycyrrhizin-treated } \\
2 \mathrm{mg} / 100 \mathrm{~g} / \mathrm{d} .5 \mathrm{~d} .\end{array}$ & 5 & $38.90 \pm 2.38 * * * *$ & $19.14 \pm 1.14 * * * * *$ & $9.35 \pm 0.65 * * *$ & $6.43 \pm 0.50 * * *$ \\
\hline $\begin{array}{l}\text { Rate of increase by } \\
\text { glycyrrhizin treatment } \\
\text { (control: 1) }\end{array}$ & & 1.9 & 2.3 & 1.5 & 1.3 \\
\hline $\begin{array}{l}* \text { Mean } \pm \text { standa } \\
* * * * * \mathrm{p}<0.001\end{array}$ & $\begin{array}{l}\text { ard erro } \\
+\mathrm{Pe}\end{array}$ & $\begin{array}{l}* * \text { Non-signi } \\
\text { centage of dpm ex }\end{array}$ & $\begin{array}{l}* * * \mathrm{p}<0.05 \\
\mathrm{~d} / \mathrm{dpm} \text { injected }\end{array}$ & $* * * * \mathrm{p}<0.01$ & \\
\hline
\end{tabular}

rrhizin treatment. The rates of increase by glycyrrhizin in radioactivities of both total ${ }^{14} \mathrm{C}$ and total bile acids${ }^{14} \mathrm{C}$ were about 2 fold but those of non-saponifiable materials $-{ }^{14} \mathrm{C}$ and $3 \beta-\mathrm{OH}-$ sterols $-{ }^{14} \mathrm{C}$ remained within 1.5 fold. The analytical data as to feces collected for $96 \mathrm{hr}$ after cholesterol-4-4 $\mathrm{C}$ injection showed the similar stimulatory effect of glycyrrhizin on the fecal excretion of cholesterol.

The effects of glycyrrhizin and cortisone on the elimination of cholesterol-1-14C from blood (Table 10)
In comparison with the radioactivity recovered from the plasma of the control group, glycyrrhizin treatment significantly decreased the radioactivity. On the other hand, cortisone appeared to increase the radioactivity, but there were no statistical differences between control animals and cortisone-treated ones.

\section{Discussion}

As we reported previously, cortisone in- 
Table 10. The effect of glycyrrhizin or cortisol administration on the elimination of cholesterol-4- ${ }^{14} \mathrm{C}$ from peripheral blood

\begin{tabular}{|c|c|c|c|c|}
\hline & & $\begin{array}{l}\text { Number of } \\
\text { animals }\end{array}$ & $\begin{array}{l}\text { Radioactivities in } \\
\text { plasma }(\mathrm{dpm} / \mathrm{m} l)\end{array}$ & $\begin{array}{c}\text { Plasma } \\
\text { cholesterol }(\mathrm{mg} / \mathrm{m} l)\end{array}$ \\
\hline & Adx. & 6 & $9,650 \pm 520 *$ & $0.84 \pm 0.04 *$ \\
\hline II. & $\begin{array}{l}\text { Adx. } \\
\text { Cortisol-treated } \\
\quad 1 \mathrm{mg} / 100 \mathrm{~g} / \mathrm{d} .8 \mathrm{~d} \text {. }\end{array}$ & 5 & $10,600 \pm 930 * *$ & $0.89 \pm 0.04 * *$ \\
\hline III. & $\begin{array}{l}\text { Adx. } \\
\text { Glycyrrhizin-treated } \\
\quad 10 \mathrm{mg} / 100 \mathrm{~g} / \mathrm{d} .8 \mathrm{~d} .\end{array}$ & 6 & $7,290 \pm 530 * * *$ & $0.71 \pm 0.03 * * *$ \\
\hline
\end{tabular}

creased biliary excretion but slightly decreased fecal excretion of both bile acid and $3 \beta-\mathrm{OH}-$ sterols in the rats after intraperitoneal injection of cholesterol-4- ${ }^{14} \mathrm{C}$. Cortisone was also reported to accelerate gastrointestinal absorption of cholesterol-4- ${ }^{14} \mathrm{C}$ and cholic acid-4${ }^{14} \mathrm{C}$. Incorporation of acetate- $1-{ }^{14} \mathrm{C}$ into rat liver cholesterol in vivo was also increased by the cortisone when determined 15 min after labeled acetate injection (Kumagai et al., 1966b). Shibata (1962) demonstrated that a small amount of glycyrrhizin increased both bile acids and cholesterol excretion into both bile and feces in the rabbits fed a lanolin-rich diet.

In this paper, it is reported that intramuscularly administered glycyrrhizin and cortisone had a stimulatory effect on the hepatic cholesterogenesis in vitro in the rats, and the effect was much greater in the glycyrrhizintreated than in the cortisone-treated. Total cholesterol content in the liver of animals treated with cortisone plus a small dose of glycyrrhizin did not differ from that of the control animals. This may presumably be due to increased excretion of bile acids and cholesterol into bile and feces, irrespective of the stimulated cholesterol biosynthesis in the liver treated with cortisone plus glycyrrhizin. The combined treatment of cortisone and glycyrrhizin showed a difference in cholesterogenesis in the liver depending on the amount of glycyrrhizin used, a smaller effect being obtained with a larger dose of the drug. This may be explained by the fact that the liver treated with a large dose contained more cholesterol than that treated with a small dose, presumably due to less excretion of bile acids and cholesterol into the bile and feces (Shibata, 1962). It is also conceivable that a smaller stimulatory effect on cholesterogenesis obtained with combined administration of cortisone plus a large dose of glycyrrhizin compared with a large dose of glycyrrhizin is due to an increased gastrointestinal absorption of cholesterol by cortisone (Kumagai et al., 1966b) and a relatively smaller stimulatory effect of a large dose of glycyrrhizin on biliary excretion of cholesterol and bile acids than a small dose of glycyrrhizin (Shibata, 1962).

As shown in table 6, when a high level of cholesterol in both plasma and liver was produced by bile duct ligation, in vivo incorporation of acetate into cholesterol did not increase by glycyrrhizin treatment so much as in the non-ligated animals. Cholesterol biosynthesis was reported to be enhanced by the bile duct ligation notwithstanding high cholesterol and bile acid contents in both liver and plasma (Fredrickson et al., 1954; Weis and Dietschy, 1969). The ligation of the bile duct masked the stimulatory effect of glycyrrhizin on the biliary excretion of cholesterol and bile acids which might reflect on hepatic cholesterogenesis.

The in vitro addition of glycyrrhizin stimulated cholesterogenesis in the liver to a small extent. It could be suspected, therefore, that 
glycyrrhizin might be relatively easily accessible to the metabolic site within the cells or might affect some mediater(s) which originate from the cell membrane and regulate cholesterogenesis. It is possible that the accumulation of metabolic products within the cells in in vitro studies might cause the smaller effect of glycyrrhizin on cholesterogenesis, compared with that shown in the experiment where glycyrrhizin was administered in vivo.

Direct demonstration was made in this paper as to the stimulatory effect of glycyrrhizin on the biliary and fecal excretion of cholesterol and bile acids after labeled cholesterol injection (Table 8 and 9). The rates of increase by glycyrrhizin pretreatment in radioactivities excreted into bile were greater in taurocholic acid than in either taurochenodeoxycholic acid or cholesterol. The rates of increase by glycyrrhizin in radioactivities excreted into feces were also larger in total bile acids than in cholesterol.

It was reported that thyroxin which had a hypocholesteremic effect decreased cholic acid and increased chenodeoxycholic acid excretion into bile (Eriksson 1957). It is conceivable, therefore, that the increasing effect of glycyrrhizin on the biliary excretion of bile acids might not be mediated by thyroxin.

Notwithstanding the stimulatory effect of glycyrrhizin on cholesterol biosynthesis, the enhanced bile acid-formation, the increased biliary excretion of both cholesterol and bile acids, the stimulated fecal excretion of cholesterol and bile acids and the acceleration of plasma cholesterol elimination might explain the cholesterol-lowering action of glycyrrhizin.

\section{Acknowledgement}

The authors are indebted to Prof. Yuichi Yamamura, The Third Department of Internal Medicine, Osaka University for his helpful suggestion and to Miss Hiromi Katoh for her technical assistance.

\section{References}

Dole, V. P. (1956). J. Clin. Invest. 35, 150.

Eriksson, S. (1957). Proc. Soc. Exptl. Biol. Med. 94, 578.

Fletcher, M. J. (1968). Clinica Chimica Acta 22, 393.

Fredrickson, D. S., A. V. Lond, B. T. Hinkelman, H. S. Schneider and I. D. Frantz, Jr. (1954). J. Exp. Med. 99, 43.

Hara, S., M. Takeuchi, M. Tachibana and G. Chihara (1964). Chem. Pharm. Bull. (Tokyo) 12, 483.

Kumagai, A., M. Otomo, S. Yano, N. Takeuchi, K. Nishino, H. Ueda and M. Kitamura (1957). Endocrinol. Japon. 5, 122.

Kumagai, A., K. Nishino, M. Yamamoto, M. Nanaboshi and Y. Yamamura (1960a). Ibid. 13, 416.

Kumagai, A., M. Yamamoto, S. Yano and Y. Yamamura (1966b). Ibid. 13, 46.

Leffler, H. H., F. W. Sunderman and F. W. Sunderman, Jr. Lipids and the steroid hormones in clinical medicine. J. B. Lippincott Co., Philadelphia, p. 18 (1960).

Shibata, N. (1962). Medical J. Osaka University 12, 297.

Sperry, W. M. (1963). J. Lipid Res. 4, 221.

Weis, H. J. and J. M. Dietschy (1969). J. Clin. Invest. 48, 2398. 